\title{
A COMUNIDADE POLONESA BRASILEIRA NAS PÁGINAS DA REVISTA "KULTURA" (ANOS 50)
}

\author{
Polish Diaspora in the Paris 'Kultura' Magazine (the 50s)
}

\author{
Anna JAMROZEK-SOWA \\ Uniwersytet Rzeszowski \\ Universidade de Rzeszów, Polônia \\ ajamrozek@ur.edu.pl \\ https://orcid.org/0000-0002-2059-581X
}

RESUMO: O artigo aborda a questão da apresentação da diáspora polonesa no Brasil nas páginas da Kultura, importante periódico da emigração polonesa do pós-guerra, que reunia excelentes jornalistas e escritores poloneses emigrados. O fundador e redator-chefe da Kultura, publicada em Paris, foi Jerzy Giedroyć. Essa revista foi publicada entre os anos de 1947 a 2000. Tinha a ambição de atender os poloneses que viviam em diferentes continentes, bem como na Polônia, onde era entregue ilegalmente. Havia um empenho para propagar em suas páginas as concepções políticas e artísticas antitotalitárias ocidentais, bem como construir o interesse do leitor ocidental sobre a Polônia e, mais amplamente, sobre os países da Europa Central que permaneciam sob esfera de influência da União Soviética. Os governos comunistas consideravam a revista particularmente perigosa, devido às visões políticas propagadas, à eficiência em alcançar os destinatários, bem como à consequente formação de relações de boa vizinhança com os vizinhos orientais da Polônia. O Brasil e os imigrantes de origem polonesa que viviam nesse país eram objeto de interesse dos redatores da Kultura. Esse objeto raramente aparecia como tema de discurso na Kultura, por causa da ausência de um colaborador permanente morando no país e pela distância da Europa. Com isso, cada artigo com a temática brasileira era importante. Nos anos 1950, falaram nas páginas da Kultura principalmente imigrantes conhecidos na comunidade da diáspora polonesa, provenientes da emigração no período da Segunda Guerra Mundial, que trataram temas importantes, tanto para seu ambiente (como, por exemplo, relações com o governo brasileiro, status social dos emigrantes, condições econômicas) como para emigrantes poloneses espalhados pelo mundo. PALAVRAS-CHAVE: Migração política polonesa; Diáspora polonesa no Brasil; Revista parisiense "Kultura"; Jerzy Giedroyć.

Tradução do resumo: Milena Woitovicz Cardoso 


\begin{abstract}
The article deals with the topic of a presentation of the Polish diaspora in Brazil in the Paris Kultura magazine. For the postwar Polish migrants, the Kultura magazine was an important journal, bringing together outstanding Polish journalists and émigré writers. The journal was published in Paris from 1947 to 2000. Its founder and editor-in-chief was Jerzy Giedroyć. The magazine aimed to reach Poles living on different continents as well as those in Poland where it was delivered illegally. Its aspiration was to promote Western, antitotalitarian political and artistic concepts and arouse the interest of the Western audience not only in Poland, but also more broadly, in Central European countries remaining under the Soviet influence. Due to political views propagated in the journal, its effectiveness in reaching readers, as well as consistency in shaping good neighbourly relations with Poland's eastern neighbours, the Polish communist authorities considered Kultura magazine particularly dangerous. The editors were interested in Brazil and its Polish diaspora; however, due to the lack of local collaborators and geographical distance from Europe, those subjects were rarely covered in the magazine. Therefore, every article concerning Brazil was considered important. In the 1950s, most of the publishers were notable personalities of the Polish diaspora, deriving from the post war migrants. In their articles they were discussing issues relevant to their local community (e.g. relations with the Brazilian government, social status of migrants, economic conditions), as well as matters concerning Polish migrants around the world. KEY WORDS: Polish Political migration; Polish Diaspora in Brazil; the Paris 'Kultura' magazine; Jerzy Giedroyć.
\end{abstract}

STRESZCZENIE: Artykuł podejmuje kwestię sposobu prezentacji brazylijskiej Polonii na łamach „Kultury”, ważnego czasopisma powojennej emigracji polskiej, skupiającego wybitnych polskich publicystów i pisarzy emigracyjnych. Założycielem i redaktorem naczelnym wydawanej w Paryżu „Kultury” był Jerzy Giedroyć. Pismo ukazywało się od 1947 do 2000 roku. Miało ambicję docierania do Polaków mieszkających na różnych kontynentach, a także w kraju, do którego był dostarczane nielegalnie. Starało się propagować na swych łamach zachodnie, antytotalitarne koncepcje polityczne i artystyczne oraz budzić zainteresowanie czytelnika zachodniego Polską, szerzej - krajami środkowoeuropejskimi pozostającymi w strefie wpływów Związku Radzieckiego. Władze komunistyczne uznawały je za szczególnie niebezpieczne ze względu na szerzone poglądy polityczne, skuteczność w docieraniu do odbiorców, a także konsekwencję w kształtowaniu stosunków dobrosąsiedzkich ze wschodnimi sąsiadami Polski. Brazylia i żyjący w niej imigranci polskiego pochodzenia była obiektem zainteresowania redaktorów „Kultury”. 
Jako temat wypowiedzi nieczęsto pojawiała się w „Kulturze”, co było spowodowane brakiem stałego współpracownika mieszkającego w tym kraju oraz odległością od Europy. Każdy artykuł o tematyce brazylijskiej był ważny. W latach 50 głos na łamach „Kultury” zabierali przede wszystkim emigranci rozpoznawalni w środowisku polonijnym, wywodzący się $\mathrm{z}$ tzw. emigracji drugowojennej. Wypowiadali się na tematy istotne, tak dla ich środowiska (np. relacje z brazylijskim rządem, status społeczny emigrantów, warunki ekonomiczne), jaki i emigrantów polskich rozsianych po świecie. SŁOWA KLUCZOWE: polska migracja polityczna; Polonia brazylijska; paryska „Kultura”; Jerzy Giedroyć

Dentre os recortes de imprensa mantidos na sede da revista parisiense Kultura em Maisons-Laffitte encontra-se um breve artigo dedicado à situação política do Brasil de 1970. Em abril daquele ano, Jerzy Putrament, um dos mais influentes literatos da Polônia pós-Segunda Guerra Mundial, homem excepcionalmente bem relacionado, com ligações com o governo, publicou nas páginas da edição de domingo do mais importante diário polonês, o Trybuna Ludu, órgão do Partido Unificado dos Trabalhadores Poloneses, um artigo acerca da atuação, no Brasil, de grupos paramilitares, os chamados "esquadrões da morte". O autor esclarece que tais grupos reúnem ex-policiais que sequestram e matam pessoas suspeitas de possuírem visões liberais ou de oposição ao governo, pois "a polícia oficial, apesar da tortura, não pode negociar com a oposição e a luta armada. Assim, cria-se um terrorismo governista ilegal"1 (PUTRAMENT, 1970). Putrament esclarece que a polícia civil também se ocupava da perseguição aos comunistas, assim como a polícia política e também a militar. Por que, então, foi precisamente este breve artigo a despertar tanto o interesse dos redatores da revista mensal Kultura, para que o preservassem durante anos? Foi decisiva a conclusão de Putrament, convencido de que o refinamento das atrocidades efetuadas pelos "esquadrões da morte" tem relação com a política levada a cabo pelos representantes da chamada "Civilização Ocidental", da revista Kultura, publicada em Paris, e da Rádio Wolna Europa. O artigo é encerrado pelo seguinte parágrafo:

as experiências da Gestapo não foram em vão. Foram aprendidas pelos defensores do capitalismo na América Latina, apoiados e pagos pelos Estados Unidos. Em nome de quê? Em nome, é claro, da liberdade, da civilização ocidental, da "Cultura parisiense" (PUTRAMENT, 1970).

\footnotetext{
${ }^{1}$ As traduções são de autoria de Luiz Henrique Budant.
} 
Fazer da revista polonófona de emigração uma corresponsável por assassinatos efetuados em outro hemisfério demonstra o tamanho do incômodo dos comunistas em relação ao periódico parisiense.

De que, pois, foi acusada a revista Kultura, que motivos tinham aqueles que a redigiam? Por que Putrament via nela uma ameaça tão grande e sugeriu uma força de atuação tão grande?

A revista Kultura existiu entre 1947 e 1990. Nos primeiros anos, esteve sob direção das Forças Armadas Polonesas no Ocidente. Em 1948, os redatores da Kultura foram desmobilizados e tornaram-se independentes do comando das autoridades no exílio. $\mathrm{O}$ primeiro número da Kultura vem à estampa ainda em Roma, o seguinte - e até o último -, em Paris. O subtítulo era: rascunhos, contos, relatórios. Ao todo, foram 637 edições em formato de caderno, contando, cada uma, mais de cem páginas. Entre 1962 e 2010, no esteio das atividades do Instituto Literário foi publicada, também, a "revista irmã" Cadernos Históricos (171 números), nas páginas da qual foram publicados, entre outros, materiais de arquivos, relatórios e análises históricas. Na série Biblioteca da "Kultura", regularmente publicavam-se livros, mencione-se, entre outros, as primeiras edições de Czesław Miłosz e Witold Gombrowicz.

A revista era redigida pela Equipe da Kultura. O núcleo da revista foi composto, ao longo de muitos anos, por Jerzy Giedroyć, Józef Czapski, Gustaw Herling-Grudziński, Zofia Hertz, Zygmunt Hertz, Henryk Giedroyć e Juliusz Mieroszewski. Tinha proeminência o papel de seu redator-chefe, Jerzy Giedroyć, conhecido como "o Príncipe de Laffitte". Como destacam os pesquisadores da revista, ela se alimentava da diversidade de seus colaboradores. Apreciavam-se situações de confronto, de discussão, de controvérsia, de desacordo. De modo consciente eram apresentadas, ao mesmo tempo, visões contrárias entre si (KOREK, 2008, p. 42). Dava-se atenção, contudo, sempre a uma perspectiva de mediação entre as razões distintas, aos debatedores em confronto. A revista Kultura tinha a ambição de alcançar o leitor fora da Polônia, além daqueles que estivessem dentro da Polônia comunista pós-Ialta, o que era exceção naquela época. Ela aceitava os chamados "novos emigrantes", isto é, aqueles que saíram da Polônia nos anos 50 (o caso de Czesław Miłosz, por exemplo). Em suas páginas, buscava propagar concepções políticas e artísticas ocidentais, antitotalitárias, além de despertar o interesse do leitor ocidental pela Polônia, ou, de modo mais geral, pelos países da Europa Central que haviam ficado na área de influência da União Soviética. Consideravam-se fundamentais para uma futura Polônia não comunista as boas relações com a Ucrânia, a Belarus e a Lituânia (naquela altura, repúblicas soviéticas cujos territórios outrora constituíram parte do território da 
República da Polônia, aos quais se chamava de $K r e s y^{2}$ ). A situação era tão complexa que parte significativa dos emigrantes poloneses para o ocidente originava-se daquela região perdida pela Polônia A revista Kultura também teve grandes méritos como espaço de publicação de belas-letras. O texto laudatório lido por ocasião da concessão do título de doutor honoris causa da Universidade Iaguelônica a Jerzy Giedroyć trazia a opinião do ilustre estudioso de literatura Jacek Łukasiewicz:

é difícil de imaginar o que seria, neste momento, a cultura polonesa sem a publicação da revista [Kultura] pelo Instytut Literacki, sem a Biblioteca da Kultura, sem os livros de Miłosz, Gombrowicz, Herling e Wat então publicados, sem os Cadernos Históricos e sem a série Documentos, sem aquele espaço de pensamento sobre as questões polonesas, impactando a opinião na Polônia e entre a emigração, influenciando no espaço ocupado pelo meio intelectual europeu (DOKTORAT..., 2005, p. 1112).

A biógrafa de Jerzy Giedroyć chamou os correspondentes da revista Kultura, espalhados por todo o mundo, de soldados lutando por uma visão comum da Polônia livre. Escreve ela:

Giedroyć construiu seu próprio exército. Tem soldados na Guatemala, na Argentina, Inglaterra, Suíça, Bélgica, EUA, México, na Itália, na França e, também, na República Popular da Polônia. Em cada um deles, uma compreensão distinta da polonidade, sem os obstáculos da disciplina dos guetos, incontidos pelo comportamento de manada. A revista Kultura se fazia conhecer por suas visões, surpreendia pela mutabilidade, chocava por tocar em tabus. Os soldados nunca se encontravam todos juntos (GROCHOWSKA, 2014, p. 126).

Em que momento da atividade editorial de Giedroyć apareceu o tema do Brasil e dos imigrantes de origem polonesa que viviam no país? Em 1946 surge, em Roma, o Instytut Literacki, que era dirigido por Jerzy Giedroyć. No esteio das atividades editoriais do Instytut Literacki, foi publicado um guia voltado para soldados das divisões polonesas que, na expectativa do final da guerra, da desmobilização e da divisão do mundo durante a Guerra Fria, estavam diante da necessidade da escolha de um lugar para dar sequência a suas vidas (no caso de escolherem não voltar ao país natal). O livro trazia o título de Informe sobre o Império Britânico e os países da América do Norte e do Sul. Nas aproximadas 150 páginas havia informações sobre a geografia, a economia, o

\footnotetext{
${ }^{2}$ Em português - as margens (Nota da redação).
} 
sistema jurídico dos países e, também, sobre a presença ou ausência de uma comunidade polonesa. O Brasil foi mencionado em penúltimo lugar, antes da Argentina, no catálogo de países da América Latina. Ao país dedicavam-se seis páginas (BRAZYLIA, 1946, p. 114-119). A leitura dos dados permitia a formação da imagem de um país no qual, apesar de uma numerosa comunidade polonesa, os soldados profissionais, com formação humanística e até mesmo engenheiros que, ao longo dos últimos anos foram privados da possibilidade da prática de seu ofício, teriam dificuldades de conseguir direito de estada permanente e de encontrar um trabalho satisfatório. $\mathrm{O}$ Brasil, que àquela altura se desenvolvia economicamente, precisava de profissionais úteis para o trabalho no campo e nas indústrias. O reconhecimento de diplomas era quase impossível:

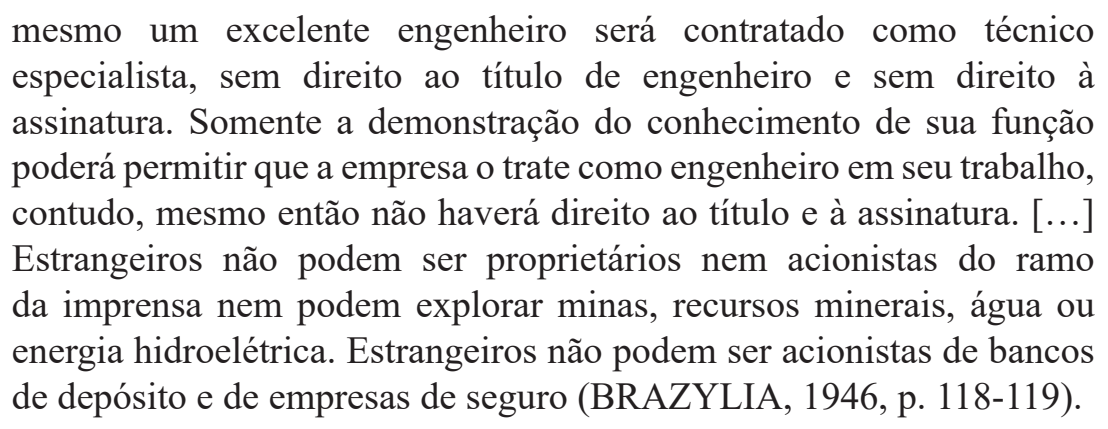

As informações sobre a situação material da maioria da comunidade polonesa local também não soaram especialmente positivas para os eventuais imigrantes. Poderiam causar apreensão as notícias de que boa parte dos agricultores trabalhava em glebas pouco férteis:

com exceção da colônia no Paraná, as fazendas polonesas localizamse em áreas climáticas pouco férteis, onde a terra não serve para o cultivo de produtos de maior valor, as dificuldades de mercado são ainda maiores [...]. O estado de São Paulo, mais rico e com maior cultura agrícola, apresentava, em 1940, 170.00 fazendas agrícolas ou de pecuária, dessas, apenas 148 eram de proprietários poloneses (BRAZYLIA, 1946, p. 117).

A redação da revista Kultura dava grande atenção à distribuição. Em 1949, o Instituto conquistou o direito à distribuição pelo correio. Para conquistar leitores permanentes, passou-se a publicar, na terceira capa de cada número, o nome e o sobrenome dos representantes junto aos quais, fora da França, seria possível encomendar uma edição. Em 1949 (n. 23), encontrava-se entre os representantes Julia Barcińska, moradora do Rio 
de Janeiro; no ano seguinte, Zofia Kietlińska, de Curitiba (1950, n. 35). Em 1951 (n. 47), o número de distribuidores ampliou-se com Walery Bador, de São Paulo; em 1953, com Hanna Lukszycka, também de São Paulo.

Como tema, o Brasil não foi uma personagem frequente nas páginas da revista Kultura. Apenas esporadicamente apareciam sobre o país na seção Crônicas ${ }^{3}$. Isto não significa, contudo, que o maior país da América do Sul fosse de pouco interesse para Giedroyć. Parece que foi decisiva a falta de um colaborador permanente que habitasse terras brasileiras, assim como faltava um literato de destaque, como foi o caso de Czesław Straszewicz, no Uruguai, ou de Andrzej Bobkowski, na Guatemala, a isso some-se, com toda certeza, a distância de milhares de quilômetros até a França. Nos anos 50 e 60, as páginas da revista Kultura deram voz, em grande medida, a emigrantes reconhecidos em seu meio, politicamente e socialmente engajados, com formação acadêmica e que já publicavam nas páginas do Lud curitibano ou do Przegląd Polonijny paulistano, originário, principalmente, da emigração ocorrida no período da Segunda Guerra. Publicada no número 4 da revista Kultura, de 1953, na seção Cartas para a Redação, o texto de Jerzy Rostworowski, do Rio de Janeiro, constitui-se como a primeira voz importante que chegou a Paris, partindo do Brasil (ROSTWOROWSKI, 1953, p. 151-152). O texto trazia reflexões sobre uma enquete efetuada pela revista Kultura entre a comunidade polonesa mundial. Rostworowski agradecia aos redatores pela ideia de analisar a situação material, legal e moral dos emigrantes poloneses:

com grande apreço recebemos aqui, no Brasil, a enquete da revista Kultura. Não sabemos quantas pessoas responderão, mas mesmo que a enquete seja respondida por apenas um pequeno percentual, o material colhido será certamente muito interessante e com grande interesse acompanharemos o anúncio dos resultados e conclusões (ROSTWOROWSKI, 1953, p. 151-152).

$\mathrm{Na}$ opinião do missivista, a revista Kultura tomou uma iniciativa que já há muito deveria ter partido das autoridades do governo no exílio, em Londres. Escreve Rostworowski:

\footnotetext{
${ }^{3}$ As Crônicas eram uma seção fixa da revista Kultura. Eram escritas pelos emigrantes espalhados ao redor de todo o mundo. Elas eram fundamentais para a linha programática da revista, tinham viva recepção, constituindo, então e agora, uma excelente fonte de informação sobre a vida quotidiana da diáspora polonesa, tendo seu valor documental reconhecido por vários pesquisadores. Para mais informações sobre as Crônicas, veja-se HOFMAN, 2004, p. 183-199.
} 
O sétimo ano desde o final da guerra traz uma série de reflexões. Ao longo deste tempo, muitas das visões de até então precisaram passar, necessariamente, por revisões. A momentaneidade do 'período de transição' ganhou traços de estabilidade, o 'fazer as malas' para de pronto retornar ao país mostra seu vazio interior (ROSTWOROWSKI, 1953, p. 151-152).

Para o escritor, os compatriotas assentados nas antípodas estavam profundamente ligados ao destino de toda a sociedade na emigração, desejavam mentalmente participar de sua vida e dividir com ela sua vida e experiências particulares, o aqui e o agora. Queriam conquistar uma voz, ser escutados e ouvidos pelos representantes das estruturas do governo polonês no exílio, responsáveis pela manutenção da valorosa comunidade construída pelos migrantes poloneses. A única crítica referia-se à ausência, na enquete, de uma pergunta sobre a cidadania e eventuais intenções de mudá-la. A posse de cidadania do país de chegada relacionava-se fortemente com a pertença nacional dos nascidos já fora da Polônia ou da Europa. Era uma questão de grande peso, fundamental - não se referia apenas à política, mas às relações familiares, íntimas, a convicções particulares. A sugestão de traição da causa nacional é absolutamente fora de lugar. "Nossa polonidade não pode estar no passaporte, mas na relação com as questões polonesas" (ROSTWOROWSKI, 1953, p. 152). Este artigo inscreve-se no ciclo de publicações programáticas a debater a questão da relação dos emigrantes para com o país de chegada, outros meios emigrantes e, enfim, para com os poloneses que permaneceram na Polônia ${ }^{4}$.

No número seguinte (o $5^{\circ}$ de 1953 , o $67^{\circ}$ de toda a numeração), publicou-se um artigo de duas páginas, intitulado "Crônica Brasileira”, de autoria de Stanisław Fischlowitz (tendo sido antecedida por uma "Crônica inglesa" e sucedida por uma "Crônica australiana"). No mencionado artigo, Fischlowitz expôs sua visão acerca da estratégia desejável pela política polonesa de emigração no contexto do, em sua opinião, inevitável confronto do Ocidente com o Oriente comunista. "Talvez não deva restar dúvida - escreveu já na primeira frase - que a estratégia política polonesa deve se desenvolver em duas linhas" (FISCHLOWITZ, 1953, p. 104). Por um lado, existia a necessidade de fortalecimento dos principais centros de emigrantes, por outro, convinha atuar em territórios até então marginalizados pelo Ocidente, tomado de maneira ampla. Os esquecidos lembravam-se, então, de sua existência e de seu significado. Prova disto é, por exemplo, a criação da

\footnotetext{
${ }^{4}$ Nos anos 50, foram considerados de fundamental importância os seguintes depoimentos: DUNIN, 1952, p. 107-117; MIEROSZEWSKI, 1953, p. 3-15; ZARZEWSKI, 1953, p. 3-22; MIEROSZEWSKI, 1954, p. 51-63.
} 
Sociedade Brasileira da Europa Livre, uma organização cujo objetivo era a formação do pensamento dos brasileiros acerca do sentido e das consequências políticas internacionais da divisão europeia no contexto da Guerra Fria. Esta sociedade - escreve Fischlowitz -

totalmente independente e autônoma juntou em si uma colaboração harmônica não apenas com representações das colônias búlgara, estoniana, lituana, letã, romena, húngara, tcheca, ucraniana e polonesa, mas também com os mais influentes agrupamentos políticos brasileiros de todos os matizes do pensamento democrático. (...) Esta atuante e influente associação foi montada, dirigida e, em grande medida, financiada por Henryk Alfred Spitzman Jordan, ativista social, presidente da Comissão do Tesouro Nacional, empresário, financista e filantropo polonês, a cuja iniciativa se deve creditar os trabalhos da Sociedade, bem como a participação do senador Chateaubriand, que deixou à sua disposição o poderoso grupo Diários Associados, assim como do dr. Roberto Marinho, proprietário do jornal $O$ Globo, de imensa tiragem, e de todos os outros ativistas brasileiros (FISCHLOWITZ, 1953, p. 105).

O autor termina sua intervenção com o desejo de que os centros de emigração sigam o exemplo brasileiro, unificando em um esforço comum "de representatividade dos outros povos da Europa Central e Oriental, hoje subjugados, mas amanhã ou depois, livres e independentes" (FISCHLOWITZ, 1953, p.105).

A próxima intervenção relativa à emigração polonesa no Brasil é de 1954 (número 11). Foi colocada no setor "Documentos do momento", que juntava materiais que a redação considerasse importantes, mas que não refletissem sua visão. Resolução do Tesouro Nacional, publicada no Brasil, tratava da questão da retirada, pelo governo polonês no exílio em Londres, do direito ao voto de uma grande massa de emigrantes e da provável colocação de entraves para a realização de empréstimos pelo Tesouro Nacional na emigração. A opinião dos autores da resolução é repreendida e leva a uma inevitável perda de confiança dos tomadores de decisão e, no futuro, impossibilitará o funcionamento das instituições governamentais polonesas de emigração. A resolução é encerrada por um parágrafo de reprimenda, mas, concomitantemente, com um apelo dirigido às autoridades e aos emigrantes:

a consecução das agendas nacionais na emigração serve para uma boa política externa (...) a busca de entendimento e de uma ação em comum com os povos que se encontram em situação análoga, bem como uma ativa colaboração com a migração com o objetivo de a manter em estado de alerta nacional (...) A emigração é a verdadeira população da República da Polônia no exterior. Tem direito ao voto e à participação 
na luta pela Independência, pela Liberdade e pela Integridade da República. De outra maneira, seria olvidado o mais importante trunfo na luta em que ora nos engajamos (SKARB ..., 1954, p. 59).

O mais longo texto dedicado à análise da estrutura e da história da emigração polonesa no Brasil foi publicado na revista Kultura em dezembro de 1958. No volume anterior, havia sido publicado o primeiro fragmento de um livro escrito por encomenda do redator-chefe, constituindo-se como uma reportagem e como um trabalho sociológico sobre a comunidade dos poloneses assentados na Grã-Bretanha após a II Guerra Mundial ${ }^{5}$. Giedroyć escreveu, àquela altura, a um de seus correspondentes permanentes, que deposita grande esperança na pronta publicação de mais um trabalho sobre a emigração, desta vez acerca das condições da comunidade polônica no Brasil. O autor do texto encomendado era Jan Wójcik. A primeira parte de Poloneses no Brasil apareceu no setor "Questões e apontamentos", levando consigo o subtítulo: Quem quebrará o silêncio? (WÓJCIK, 1958, p. 103-127). Este conhecido ativista e publicista partiu da premissa que a dor essencial dos meios polônicos no Brasil é o grande desconhecimento sobre sua existência. Parecelhe um paradoxo a falta de conhecimento, por parte dos brasileiros, do grande número de poloneses residentes no Brasil. Surpreendeu-lhe que mesmo os moradores do estado sabem pouco ou quase nada sobre a contribuição dos imigrantes para o desenvolvimento e o enriquecimento do Brasil. Os imigrantes poloneses, afirma Wójcik, estão presentes fisicamente, mas sua existência permanece, até agora, sem reconhecimento dos outros que vieram ao Brasil no contexto dos movimentos migratórios.

Não se pode afirmar que um brasileiro médio não saiba sobre os poloneses. Esta consciência, contudo, é um saber vacilante, indiferente sobre um determinado grupo de trabalhadores e agricultores que são caracterizados como decentes, "pessoas boas" e, sobretudo, como pessoas cuja distante e exótica pátria é uma terra "heroica" e muito "sofrida" (WÓJCIK, 1958, p. 103)

As causas deste estado de coisas, Wójcik buscou sobretudo na falta de estruturas nacionais cujos representantes pudessem prestar assistência a seus compatriotas. O Estado Polonês, se existisse já no início da migração para o Brasil, tornar-se-ia um defensor

\footnotetext{
${ }^{5}$ A carta do Jerzy Giedroyć para Bogdan Czaykowski de 30 de junho de 1958. Listy Jerzego Giedroycia do Bogdana Czaykowskiego z lat 1956-1995, acervo da BUW (Biblioteca da Universidade de Varsóvia), número de inventário 4982. O livro mencionado da autoria de Bogdan Czaykowski e Bolesław Sulik, intitulado Polacy w W. Brytanii foi publicado em Paris no ano 1961 em uma série da Biblioteka Instytutu Literackiego.
} 
do bem-estar e do bom nome de seus representantes, enviando d'além mar grupos bem organizados e preparados para se oporem às dificuldades da "alteridade". Wójcik considerou como problemas fundamentais da comunidade polônica brasileira, no final dos anos 50: o envelhecimento (a falta de um fluxo de novos emigrantes vindos da Polônia ou de outros lugares de residência temporária), assim como a manutenção da memória e da língua em tamanha distância do país de origem. À forte voz de Jan Wójcik, reagiu grato um leitor, o Pe. Wojciech Sojka, de Curitiba: "Pelo artigo [...] deve-se verdadeira gratidão ao autor e à Redação. 'Finalmente fomos descobertos' pela imprensa polonesa" (LISTY..., 1959, p. 147). Este mesmo padre Sojka, no número 6 de 1959, apresentou um texto de várias páginas completando um retrato da vida da comunidade polônica (a leitura, a imprensa polonesa, os livros publicados) (A.Z., 1959, p. 99-103).

O Brasil e os imigrantes de origem polonesa que nele viviam seguiram sendo objeto de interesse dos redatores da revista Kultura nas décadas seguintes (nos anos 70, contudo, não apareceu nenhum “texto brasileiro"). Nas páginas da revista Kultura, a pena de Jan Wójcik criticou livros de reportagens publicados contemporaneamente na Polônia (Szumia dęby nad Iguassu de Antoni Olcha [Farfalham os salgueiros sobre o Iguaçu], e Między Wielką Niedźwiedzica a Krzyżem Poludnia, de Eugeniusz Gruda [Entre a Ursa Maior e o Cruzeiro do Sul]) ${ }^{6}$. Foram esclarecidos os segredos do funcionamento das sociedades anônimas, os quais chocavam a opinião pública (SZWEJS, 1965, p. 129$135)^{7}$. Nos anos 80 e 90, a igreja brasileira gozou de especial interesse, a questão da fé e dos rituais, a visita do Papa João Paulo II ao Brasil (escreveram sobre tais temas Henryk Siewierski ${ }^{8}$ e Dominik Morawski ${ }^{9}$ ). Também se escreveu sobre os conflitos políticos e sociais que atingiam a América do Sul e sobre os problemas internos do Brasil, como por exemplo, os artigos de autoria de Maciej Feldhuzen ${ }^{10}$; a conversa de Henryk Siewierski

${ }^{6}$ WÓJCIK, 1960b, p. 122-134 (sobre Antoni Olcha, Szumia dęby nad Iguassu, Warszawa: Ludowa Spółdzielnia Wydawnicza, 1959); WÓJCIK, 1960a, p. 112-114 (sobre Eugeniusz Gruda, Między Wielka Niedźwiedzicą a Krzyżem Poludnia, Warszawa: Czytelnik, 1959).

${ }^{7} \mathrm{O}$ artigo trata da empresa "Compania Colonizadora del Norte S.A.".

${ }^{8}$ Por exemplo: SIEWIERSKI, 1986, p. 36-44; SIEWIERSKI, 1987, p. 56-67 (tradução da entrevista com o Pe. Leonardo Boff).

${ }^{9}$ MORAWSKI, 1980, p. 57-60; MORAWSKI, 1986, p. 67-70.

${ }^{10}$ Por exemplo: FELDHUZEN, 1988, p. 98-07; FELDHUZEN, 1989, p. 40-50. 
com o Embaixador José Osvaldo de Meira Penna (SIEWIERSKI, 1993, p. 73-80) ${ }^{11}$; e um texto da socióloga polonesa radicada nos EUA, Alicja Iwańska (1987, p. 40-44), intitulado Os descendentes brasileiros de Scarlett O'Hara, em que a autora trata dos refugiados estadunidenses que, nos tempos da Guerra Civil daquele país, emigraram para o estado de São Paulo.

Tradução: Luiz Henrique Budant

${ }^{11}$ Henryk Siewierski publicou também, entre outros, a tradução do poema A ilusão do migrante de Carlos Drumond de Andrade (DRUMOND DE ANDRADE, 1998, p. 50-51) e Lembraças do professor Agostinho da Silva (SIEWIERSKI, 1998, p. 121-123) 


\section{REFERÊNCIAS:}

A.Z. (SOJKA, W.). Migawki z Brazylii. Kultura, n. 6, p. 99-103, 1959. Disponível em: $<$ http://static.kulturaparyska.com/attachments/19/be/5b956f13da649a0c5e723bd52 bf30c5e8164ac6d.pdf\#page=51>. Acesso em 20 ago. 2020.

BRAZYLIA. In: SIUTA, T. Informator o Imperium Brytyjskimi krajach Ameryki Ptn. $i$ Ptd., Rzym: Instytut Literacki, 1946. p. 114-119. Disponível em: < http://kulturaparyska. com/pl/find/item/Publication/9804?q=\%22brazylia\%22>. Acesso em 20 ago. 2020.

CZAYKOWSKI, B.; SULIK, B. Polacy w Brazylii. Paris: Instytut Literacki, 1961.

DOKTORATHonoris CausaUniwersytetu Jagiellońskiego,In:HalinaKOSIENKOWSKA, H.; KRAWCZYK, J.; PECIAK, A. (Orgs). Jerzego Giedroycia doktoraty honoris causa, Lublin: Wydawnictwo Uniwersytetu Marii Curie-Skłodowskiej; Towarzystwo Opieki nad Archiwum Instytutu Literackiego w Paryżu, 2005. p. 11-12.

DRUMOND DE ANDRADE, Carlos. Złudzenie emigranta. Tradução de Henryk Siewierski. Kultura, n. 4/607, p. 50-51, abr. 1998. Disponível em: $<$ http://static.kulturaparyska.com/attachments/f5/e6/c52bb542af5fbf0918c054c7e0 ce50480879c54f.pdf\#page=27>. Acesso em 20 ago. 2020 .

DUNIN, P. Przechowalnia wartości moralnych. Kultura, n 12/62, p. 107-117, dez. 1952. Disponível em: <http://static.kulturaparyska.com/attachments/6d/f1/ ec5b3ed2a1472ce56b1328a315470b72d72d42ec.pdf\#page=56>. Acesso em 20 ago. 2020 .

FELDHUZEN, M. Biskup na ławie oskarżonych. Kultura, n. 12/495, O religii bez namaszczenia, p. 98-07, dez. 1988. Disponível em: <http://static.kulturaparyska. com/attachments/a5/61/e6c140738118469d03ea963d65176e069baa9c37.pdf\#page=51>. Acesso em 20 ago. 2020.

FELDHUZEN, M. Brazylia: rząd, robotnicy, Kościół. Kultura, n. 6/501, p. 4050, jun. 1989. Disponível em: <http://static.kulturaparyska.com/attachments/28/e6/ b53e1986c540de11d2dbf0e4e85f794486a4460c.pdf\#page=22>. Acesso em 20 ago. 2020.

FISCHLOWITZ, S. Kronika brazylijska. Kultura, n. 5/67, p. 104-105, maio 1953. Disponível em:<http://static.kulturaparyska.com/attachments/bd/29/2ebe0dc41b521c04 28ae0d2fcd2c96cd40b6c1bc.pdf $>$. Acesso em 20 ago. 2020.

GROCHOWSKA, M. Jerzy Giedroyć. Do Polski ze snu. Introdução de Andrzej Friszke. Warszawa: Wielka Litera, 2014. 
HOFMAN, I. Kroniki - między Krajem, emigracją i sąsiadami. In: HOFMAN, Iwona. Szkice o paryskiej „,Kulturze”. Toruń: Wyd. Adam Marszałek, 2004. p. 183-199.

IWAŃSKA, A. Brazylijscy potomkowie Scarlett O'Hara. Kultura, n. 6/477, p. 4044, jun. 1987. Disponível em: <http://static.kulturaparyska.com/attachments/c4/f4/ f1888ba3fda5eb68d7b6c1995a915b05a281841b.pdf\#page=22>. Acesso em 20 ago. 2020 .

KOREK, J. Paradoksy paryskiej „Kultury”. Style i tradycje myślenia politycznego. Katowice: Wydawnictwo Uniwersytetu Śląskiego, 2008.

LISTY do Redakcji, Kultura, n. 3/137, p. 147-148, 1959. Disponível em: <http://static. kulturaparyska.com/attachments/c0/43/0f927646f86a76ea2b7a4ff493a642cf8fea32a2. pdf $>$. Acesso em 20 ago. 2020.

MIEROSZEWSKI, J. Oblicza emigracji. Kultura, n. 4/66, p. 3-15, abr. 1953. Disponível em: $<$ http://static.kulturaparyska.com/attachments/32/78/be92846e2cce7ed78322bebc5 40572629f121587.pdf\#page=3>. Acesso em 20 ago. 2020.

MIEROSZEWSKI,J.Polacyi...poganie.Kultura,n.9/83,p.51-63, set.1954.Disponívelem: $<$ http://static.kulturaparyska.com/attachments/64/9c/d539710d036a27fb124531233eff83 0788768e31.pdf\#page=27>. Acesso em 20 ago. 2020.

MORAWSKI, D. Podróż do Brazylii widziana z Rzymu. Kultura, n. 9/396, p. 5760, set. 1980. Disponível em: <http://static.kulturaparyska.com/attachments/0a/fc/ 1d0de47fd73309c51b4e4e662abbaad34b9f24ed.pdf\#page=32>. Acesso em 20 ago. 2020.

MORAWSKI, D. Kościółi trzy dyktatury.Kultura,n.5/464,p. 67-70, maio 1986. Disponível em: <http://static.kulturaparyska.com/attachments/cd/42/c1 ee846fd02d31d8dbe86690bb 32a688d209fa8b.pdf\#page=35>. Acesso em 20 ago. 2020.

ROSTWOROWSKI, J. Listy do redakcji. Kultura, n. 4/66, Listy do redakcji, p. 151153, abr. 1953. Disponível em: <http://static.kulturaparyska.com/attachments/32/78/ be92846e2cce7ed78322bebc540572629f121587.pdf\#page=74>. Acesso em 20 ago. 2020 .

SIEWIERSKI, H. Imperium Ducha świętego. Kultura, n. 12/471, p. 36-44, dez. 1986. Disponível em: <http://static.kulturaparyska.com/attachments/59/0d/b440a8a7ff5eb6c7 9ed1469a0eb76ae7ec66c123.pdf\#page=21>. Acesso em 20 ago. 2020. 
SIEWIERSKI, H. (Trad.) Kościół ubogich: wywiad z O. Leonardo Boffem, OFM, Kultura, n. 1/472-2/473, O religii bez namaszczenia, p. 56-67, jan./fev. 1987. Disponível em: $<$ http://static.kulturaparyska.com/attachments/56b7/285fa17d2746e6d7be 7f686e $7 \mathrm{~d} 9$ 6791dd1490976.pdf\#page=30>. Acesso em 20 ago. 2020.

SIEWIERSKI, H. Brazylia: Problemy wieku przejściowego. Rozmowa z ambasadorem José Osvaldo de Meira Penna. Kultura, n. 1/544-2/545, p. 73-80, jan./fev. 1993. Disponível em: < http://static.kulturaparyska.com/attachments/89/cc/4bb99b7bb54b00bccdf9783478 739a128be68608.pdf\#page=38>. Acesso em 20 ago. 2020.

SIEWIERSKI, H. Wspomnienie o profesorze Agostinho da Silva. Kultura, n. 11/566, p. 121-123, Ci, co odeszli, nov. 1994. Disponível em: <http://static.kulturaparyska.com/ attachments/84/7f/802069e0dd95f0227d5ea202e5d9649b4719ec98.pdf\#page=62>. Acesso em 20 ago. 2020.

SKARB Narodowy w Brazylii. Kultura, n.11/85, p. 59, nov. 1954. Disponível em: $<$ http://static.kulturaparyska.com/attachments/76/4b/a96bbdc85a23c43026268ab043e9e addd987ea54.pdf\#page=31. $>$. Acesso em 20 ago. 2020.

SZWEJS, S. Sprawa “Kolonizadory”. Kultura, n. 10/216, p. 129-135, out. 1965. Disponível em: < http://static.kulturaparyska.com/attachments/95/61/e253593752d597896fb827e35a d9379b29fbf0b1.pdf\#page=66>. Acesso em 20 ago. 2020 .

WÓJCIK, J. Polacy w Brazylii: Kto przełamie ciszę? Kultura, n. 12/134, Sprawy i troski, p. 103-127, dez. 1958. Disponível em: <http://static.kulturaparyska.com/attachments/91/71/ c29a713457679a509d6a937609549698e62ea53b.pdf\#page=53>. Acesso em 20 ago. 2020.

WÓJCIK, J. Niepotrzebna książka. Kultura, n. 11/157, p. 112-114, nov. 1960a. Disponível em: < http://static.kulturaparyska.com/attachments/f4/db/1a1fla3ad72adbf961b899e9e94 a8c2cadafa705.pdf\#page $=58>$. Acesso em 20 ago. 2020 .

WÓJCIK, J.Antoni Olchaw Brazylii.Kultura, n. 12/158,p. 122-134, dez. 1960b. Disponível em: <http://static.kulturaparyska.com/attachments/82/bf/ff4353ff913d0bc86cda606c4c7 02e7315dc86ad.pdf\#page=34>. Acesso em 20 ago. 2020 .

ZARZEWSKI, S. Fetysze i fikcje emigracji. Kultura, n. 9/71, p. 3-22, set. 1953. Disponível em: $<$ http://static.kulturaparyska.com/attachments/ab/01/653962a253a8182e8d0d5c04b1 5aa7db0b0c57ce.pdf\#page=3>. Acesso em 20 ago. 2020 . 